\title{
Collembase: a repository for springtail genomics and soil quality
} assessment

\author{
Martijn JTN Timmermans*1, Muriel E de Boer ${ }^{1}$, Benjamin Nota ${ }^{1}$, Tjalf E de \\ Boer $^{1}$, Janine Mariën ${ }^{1}$, Rene M Klein-Lankhorst ${ }^{2}$, Nico M van Straalen ${ }^{1}$ and \\ Dick Roelofs ${ }^{1}$
}

\begin{abstract}
Address: ${ }^{1}$ Vrije Universiteit, Institute of Ecological Science, Department of Animal Ecology, De Boelelaan 1085, 1081 HV, Amsterdam, The Netherlands and 2PRI Greenomics, Droevendaalse steeg 1, 6708 PB Wageningen, The Netherlands

Email: Martijn JTN Timmermans* - martijn.timmermans@falw.vu.nl; Muriel E de Boer - muriel.de.boer@falw.vu.nl; Benjamin Nota - ben.nota@falw.vu.nl; Tjalf E de Boer - tjalf.de.boer@falw.vu.nl; Janine Mariën - janine.marien@falw.vu.nl; Rene M KleinLankhorst - rene.kleinlankhorst@wur.nl; Nico M van Straalen - nico.van.straalen@falw.vu.nl; Dick Roelofs - dick.roelofs@falw.vu.nl

* Corresponding author
\end{abstract}

Published: 27 September 2007

BMC Genomics 2007, 8:34| doi:| 0.| |86/|47|-2|64-8-34|
Received: 8 May 2007

Accepted: 27 September 2007

This article is available from: http://www.biomedcentral.com/|47|-2/64/8/34 I

(c) 2007 Timmermans et al; licensee BioMed Central Ltd.

This is an Open Access article distributed under the terms of the Creative Commons Attribution License (http://creativecommons.org/licenses/by/2.0), which permits unrestricted use, distribution, and reproduction in any medium, provided the original work is properly cited.

\begin{abstract}
Background: Environmental quality assessment is traditionally based on responses of reproduction and survival of indicator organisms. For soil assessment the springtail Folsomia candida (Collembola) is an accepted standard test organism. We argue that environmental quality assessment using gene expression profiles of indicator organisms exposed to test substrates is more sensitive, more toxicant specific and significantly faster than current risk assessment methods. To apply this species as a genomic model for soil quality testing we conducted an EST sequencing project and developed an online database.

Description: Collembase is a web-accessible database comprising springtail ( $F$. candida) genomic data. Presently, the database contains information on 8686 ESTs that are assembled into 5952 unique gene objects. Of those gene objects $\sim 40 \%$ showed homology to other protein sequences available in GenBank (blastx analysis; non-redundant (nr) database; expect-value $<10^{-5}$ ). Software was applied to infer protein sequences. The putative peptides, which had an average length of 115 amino-acids (ranging between 23 and 440) were annotated with Gene Ontology (GO) terms. In total 1025 peptides ( $\sim 7 \%$ of the gene objects) were assigned at least one $\mathrm{GO}$ term (expect-value $<$ 10-25). Within Collembase searches can be conducted based on BLAST and GO annotation, cluster name or using a BLAST server. The system furthermore enables easy sequence retrieval for functional genomic and Quantitative-PCR experiments. Sequences are submitted to GenBank (Accession numbers: EV473060 - EV481745).

Conclusion: Collembase http://www.collembase.org is a resource of sequence data on the springtail $F$. candida. The information within the database will be linked to a custom made microarray, based on the Agilent platform, which can be applied for soil quality testing. In addition, Collembase supplies information that is valuable for related scientific disciplines such as molecular ecology, ecogenomics, molecular evolution and phylogenetics.
\end{abstract}




\section{Background}

Organisms are able to maintain homeostasis in changing environments by regulating their metabolic machinery. To accomplish this, organisms continuously have to adjust the expression of their genes. This is particularly evident when environmental challenges drive organisms to the boundaries of their ecological niche and induce stress responses (e.g. [1]). In recent years, significant understanding has been obtained on the signal transduction pathways by which stress affects gene transcription [2]. The question arises whether it is possible to sense aspects of the environment by investigating transcriptional profiles of exposed organisms.

Recent advances in the field of toxicogenomics suggest that environmental quality can indeed be diagnosed by transcriptional profiling [3] and it is generally acknowledged that genomic techniques, and more specifically transcriptomics, have the potential to revolutionize environmental risk assessment [4-9]. The prospects are that gene expression studies will enable a fast and sensitive detection and evaluation of environmental stressors and toxicants. This is strengthened by the fact that several recent studies have shown that transcription profiling can be applied as an early indicator of toxicity $[10,11]$ in a dose-dependent manner [12].

We started a project that aims to develop a microarraybased methodology for soil quality assessment using the parthenogenetic springtail Folsomia candida (Collembola). This species, which is easy to culture and has a short generation time, was chosen because it is already a standard test organism in ecotoxicology [13]. It lives in direct contact with the soil and toxicological data are already widely available (e.g. ECOTOX database from U.S. EPA [14]). Furthermore, a standard test looking at survival and reproduction after 28 day exposure is in place that follows OECD (Organisation for Economic Co-operation and Development) and ISO (International Standard Organization) guidelines. Although the latter test is conducted in a standardized laboratory setting, it has been shown that the outcomes are predictive of natural situations [15]. However, there are several shortcomings to the current test. First, it does not provide information about the nature of the stressor. Second, the mode of action of toxicants cannot be verified. Third, the test is time-consuming as it lasts for at least 28 days. Finally, the test is rather labor intensive.

By extending the ISO standard test with genomic technologies, these shortcomings may be circumvented. However, genomic information on $F$. candida is very poor: a search for sequences yields only 52 hits in the National Center of Biotechnology (NCBI;[16]) nucleotide database (July $5^{\text {th }} 2007$ ), mainly consisting of 18 S rRNA, 28 S rRNA and cytochrome c oxidase sequences used as phylogenetic markers.

A time- and cost effective way to retrieve sequence information on the functional part of the genome is to set up an Expressed Sequence Tag (EST) project, which was conducted for the F. candida transcriptome. Here we report on the sequencing and annotation of 9000 ESTs, which form the starting point for the construction of an oligo array that can be applied in soil quality testing. The sequences were processed, assembled, BLAST-based annotated and stored in a web-accessible database [17]. The database can be searched for BLAST-based annotations and Gene Ontology terms [18] and by using a stand alone BLAST server. Collembase furthermore enables retrieval of sequence information on (differentially) expressed genes, which can then be applied in functional genomic and Quantitative-Polymerase Chain Reaction (Q-PCR) validation experiments.

Although Collembase was primarily created for the development of a microarray, we expect that it is of interest for researchers outside the field of ecotoxicology as well. Due to its short generation time, F. candida is often used in ecological studies [13]. In addition, Collembola have a crucial position in the phylogeny of the arthropods and, thus, also have the attention from evolutionary biologists (e.g. [19]). The retrieved genome data will significantly enhance molecular ecological and evolutionary studies on F. candida.

\section{Construction and content \\ Construction of cDNA libraries}

To restrict redundant sequencing we chose to start our EST project with a normalized cDNA pool. RNA extraction from the parthenogenetic, clonally reproducing collembolan Folsomia candida (laboratory strain 'Berlin'; Vrije Universiteit Amsterdam) was carried out using the Spin Vacuum (SV) Total RNA isolation system (Promega). Animals (eggs, juveniles and adult females) were taken from a culture of mixed age with a more or less even age distribution. All animals ( $100 \mathrm{mg}$ ) were pooled before RNA extraction. Concentration and purity of the total RNA pool was checked by UV absorption (260 and $280 \mathrm{~nm}$ ). Quality of total RNA was evaluated on a $1 \%$ agarose gel (stained with SYBR Gold stain; Invitrogen) and on an Agilent BioAnalyzer (Agilent Technologies). Afterwards 0.1 volumes of $3 \mathrm{M}$ sodium acetate and 3 volumes of $96 \%$ ethanol were added and total RNA was shipped at room temperature to Evrogen (Moscow, Russia).

Double-stranded cDNA synthesis (SMART technology [20]), normalization and library construction were performed by Evrogen. The reaction was started with $0.3 \mu \mathrm{g}$ total RNA and CDNA was SMART amplified (18 PCR 
cycles) and normalized by the procedure described by [21], which consists of cDNA denaturation/reassociation, a duplex-specific nuclease (DNS) treatment [22] and PCR amplification. The cDNA thus obtained was used for library construction as follows. The cDNA was incubated with restriction enzymes Sbf1 and Not1, and ligated into Sbf1 and Not1 digested pAL17.2 vector (Evrogen). The resulting plasmids were subsequently transformed into $E$. coli (Evrogen). Finally, glycerol stocks were made $(17 \%$ glycerol), which were transferred to the Vrije Universiteit (Amsterdam) on dry-ice and stored at $-80^{\circ} \mathrm{C}$ until further use.

Efficiency of the procedure was examined by determining the abundance of several transcripts before and after normalization using Q-PCR. Primers were developed based on five available GenBank accessions and $\beta$-actin. Genes amplified were $\beta$-actin (GenBank:EU037094), USP-RXR (GenBank:AY157930), Ultrabitorax (GenBank: AF435789), Kruppel (GenBank:AF395109), RNA helicase Dead1 (GenBank:AY043229) and 28S rDNA (GenBank: AF483424). Primer sequences are given on [17] (see Additional file 1). Primers were developed using Primer Express version 1.5 (Applied Biosystems Inc., Foster City, USA), using the following parameters: Minimum Tm: 59$60^{\circ} \mathrm{C}$, Maximum Tm difference between primers: $1^{\circ}$, Oligo length: 20-25 bp, Amplicon length: 90-120 bp.

Real-time PCR was performed on an Opticon 1 real-time PCR machine (MJ Research) using SYBR green 2X Mastermix (Finnzymes), according to [23]. Real time PCR reactions used $3 \mu \mathrm{l}$ normalized and non-normalized nonligated cDNA template $(0.2 \mu \mathrm{g} / 100 \mu \mathrm{l})$. The program used for amplification was: denaturation $\left(95^{\circ} \mathrm{C}\right.$ for $15 \mathrm{~min}$.), 2-step amplification and quantification $\left(92^{\circ} \mathrm{C}\right.$ for $15 \mathrm{~s}$, $60^{\circ} \mathrm{C}$ for $1 \mathrm{~min}$. and one fluorescence measurement), melting curve program $\left(60-90^{\circ} \mathrm{C}\right.$ with a heating rate of $0.1^{\circ} \mathrm{C}$ per second and one fluorescence measurement per second). As can be seen in Figure 1 the normalization procedure was effective: transcripts that were highly abundant in the original pool (Figure 1A) occurred considerably diminished after normalization (Figure 1B) as compared to lower abundant transcripts. Differences in Ct-values between the high abundant $28 \mathrm{~S}$ rRNA and $\beta$-actin transcripts and the less abundant USP-RXR and RNA helicase Dead1 transcripts was reduced from about 14 cycles to less than three cycles. However, the least abundant transcripts (Ultrabithorax and Kruppel) were not very well enriched: they maintained high Ct-values.

De Boer et al. (unpublished data) constructed cDNA libraries enriched for stress responsive genes as described by [24]. In short, 960 clones were isolated from each of two subtracted cDNA libraries enriched for 1) cadmiumand 2) phenanthrene responsive genes. Both libraries

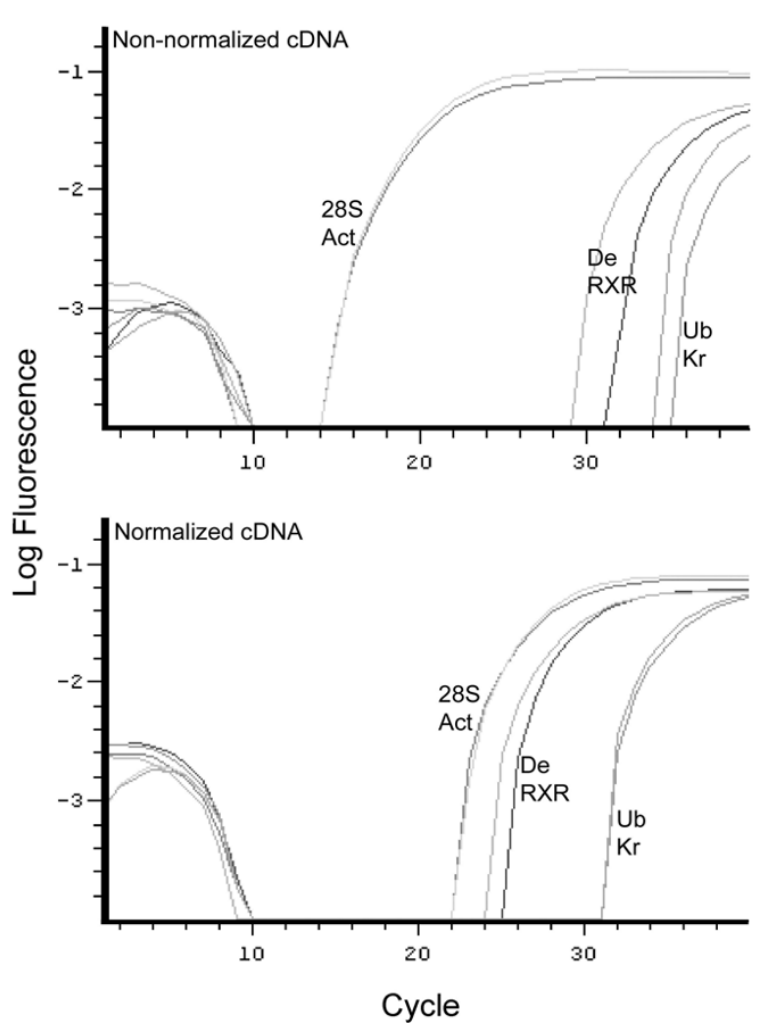

Figure I

Relative abundance of six CDNAs before (upper) and after (lower) normalization as measured using quantitative PCR. Act: $\beta$-actin; 28S: $28 S$ rDNA; De: RNA helicase Dead I; RXR: RXR-USP; Ub: Ultrabithorax; Kr: Kruppel.

were built using the suppression subtractive hybridization procedure (SSH) [25] making use of poly (A)+ RNA isolated from $~ 150$ exposed unsynchronized adult individuals (whole body; laboratory strain 'Berlin'; Vrije Universiteit Amsterdam). Exposure to cadmium was performed by placing animals on cellulose filters wetted to approximately 50\% water-holding capacity with a 267 $\mu$ mole $/ \mathrm{l} \mathrm{CdCl}_{2}$ solution for $48 \mathrm{~h}$. Animals were exposed to phenanthrene by placing them on a compressed layer of LUFA 2.2 soil spiked with $840 \mu \mathrm{m} / \mathrm{kg}$ phenanthrene according to the standard ISO11267 [26] protocol for 6 days.

\section{EST sequencing, bioinformatics and construction of the database}

In total, 9984 cDNA clones were picked and sequenced (Greenomics; Wageningen University and Research Center) using the M13 forward primer. Clones originating from the normalized library were sequenced from the $5^{\prime}$ end of the gene (8064 total). The cDNA fragments from the SSH procedure were not ligated directionally, and 
therefore not sequenced from a predefined orientation (960 clones from each of the two libraries).

Raw trace files were processed using Trace2dbest [27], employing a Phred $[28,29]$ quality threshold of 20 and a minimal high quality sequence length of 150 base pairs (bp). Of the 9984 sequences 1142 sequences did not pass the quality control, and were excluded from further analysis. A summary of the number of sequences that remained from each of the three libraries after processing of the raw data is given in Table 1 .

CLOBB [30] and Phrap (P. Green, personal communication [31]) were applied, as part of the Partigene script [27], to cluster and assemble the ESTs into unique gene objects. This procedure resulted in 6092 unique sequences. There were 4686 singletons and 1406 clusters with more than one sequence. Of those 1406 clusters 920 consisted of two sequences only. The redundancy (defined as total number of sequences/clusters) was 1.45, 1.32 and 1.62 for the total dataset, the normalized library and the cadmium library respectively, but appeared considerably higher in the phenanthrene enriched library (3.18). The highest sequence depth also occurred the phenanthrene enriched library with 98 ESTs in one cluster, compared to a maximum of 31 and 16 ESTs per cluster for the normalized and cadmium library respectively.

Sequences that were assigned to one cluster were not always assembled into one single contiguous consensus sequence (contig) by Phrap, due to high quality base pair differences between sequences. The Phrap assembly (Partigene default criteria) resulted in a total number of 6212 contigs instead of the 6092 given above (Table 2). The length of those 6212 contigs ranged between $153 \mathrm{bp}$ and $1636 \mathrm{bp}$ and was on average $520 \mathrm{bp}$ (see Additional file 2 ). The sequence variation that was observed within those clusters might constitute natural occurring (allelic) variation (e.g. Single Nucleotide Polymorphisms), Taq polymerase errors and/or gene duplications, and will have to be confirmed by re-sequencing efforts.

Furthermore, a PERL script, which is made available on [17], was used to determine the sequence overlap between the three libraries. This script determined for each cluster which library contributed ESTs to that cluster. The overlap appeared rather low (Figure 2). Only seven clusters contained sequences from each of the three libraries (Table $3)$. At least three of those clusters remained un-annotated. However, it has to be mentioned that the sequence overlap that was observed might be an underestimation of the actual overlap in the database, as 5' sequencing (Normalized library) generally results in an overestimation of the number of unique sequences [32].

The contigs were subjected to BLAST [33] searches of GenBank using blastx (against non-redundant database), blastn (against non-redundant database), tblastx (against $\mathrm{dbEST}$ ) and an additional blastx (against non-redundant database restricted to Insecta). In addition, sequences were compared to all known and predicted proteins of Caenorhabditis elegans, Drosophila melanogaster and Mus musculus. Those species were chosen as they have fully sequenced genomes. In addition, C. elegans and D. melanogaster belong, like $F$. candida, to the group of molting animals (Ecdysozoa). A summary of the BLAST analyses is given in Table 4. Clusters that were perfect nucleotide matches to baker's yeast (Saccharomyces cerevisiae; 125 clusters) and human sequences (15 clusters) were regarded as contamination and later on removed. The relatively high number of yeast clusters observed $(\sim 2 \%)$ is explained by the fact that in our laboratory $F$. candida is fed baker's yeast. The fact that the food of $F$. candida is in itself a genomic model species was advantageous when pruning the database: these sequences are readily identified by their high bit and e-values scores in the BLAST searches.

F. candida harbors intracellular bacteria of the genus Wolbachia [34] and its gut contains many bacterial species as well [35]. Those might turn up as contaminating sequences in the EST dataset. To pinpoint contaminating sequences from bacterial origin the clusters were compared to all protein encoding sequences found in the genome of Escherichia coli (GenBank: U00096) and in the Wolbachia endosymbiont of Drosophila melanogaster (GenBank: $\underline{\text { AE017196) }}$. Sequences showing significant homology to E. coli or Wolbachia (blastx; e-value $<10^{-5}$ ), but not to D. melanogaster, C. elegans or M. musculus, were marked as putative contaminants. In total 70 of such clus-

Table I: Remaining sequences after the Trace2dbest process

\begin{tabular}{lll}
\hline Library & \# Clones sequenced & \# Passed (\%) \\
\hline Normalized & 8064 & $7329(91)$ \\
Cadmium enriched & 960 & $705(73)$ \\
Phenanthrene enriched & 960 & $808(84)$ \\
\hline Total & 9984 & $8842(89)$ \\
\hline
\end{tabular}


Table 2: Contigs per cluster, as generated by CLOBB and Phrap

\begin{tabular}{|c|c|c|c|}
\hline & \# Clusters & \# Contigs/cluster & Total number of contigs \\
\hline \multirow[t]{6}{*}{ Clusters } & 1 & 11 & 11 \\
\hline & 1 & 10 & 10 \\
\hline & I & 5 & 5 \\
\hline & 7 & 3 & 21 \\
\hline & 83 & 2 & 166 \\
\hline & 1313 & I & $1313 *$ \\
\hline Singletons & 4686 & 1 & 4686 \\
\hline Total & 6092 & & 6212 \\
\hline
\end{tabular}

* In 75 instances Phrap did not assemble the contigs, in those cases the pseudo-contig files generated by PartiGene were used.

ters were retrieved, which overlapped to a great extent (56 E. coli and 32 Wolbachia clusters): In total 18 clusters appeared in both analyses (see Additional file 3). Those putative 'bacterial clusters' were not excluded from further analysis, as our procedure does not guarantee if a sequence is contamination or not.

Table 3 shows the five most abundant transcripts for each of the three libraries. The SSH procedure conducted on phenanthrene exposed animals appeared efficient. Of the top five phenanthrene clusters three show high similarities to monooxygenases of the cytochrome P450 enzyme

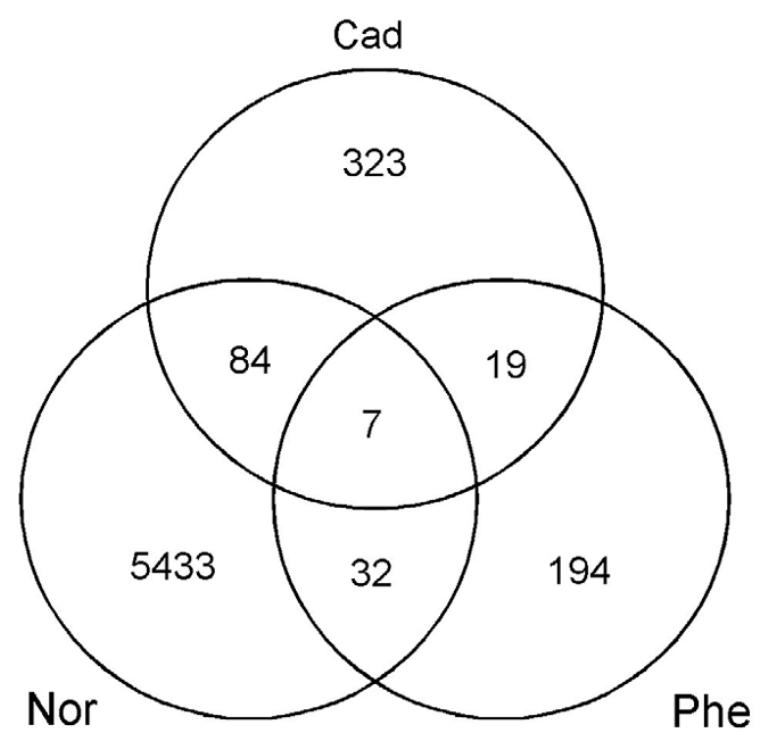

Figure 2

Venn-diagram showing the cluster overlap between the three libraries for the total dataset: Cad: cadmium enriched library; Phe: phenanthrene enriched library; Nor: normalized library. family, which are known to be involved in phase I biotransformation of lipophilic substances such as phenanthrene [36]. The two other clusters show homology to other monooxygenases, and might be involved in phase I metabolism as well. The results for the cadmium library are less straightforward. Two of the five most abundant clusters remain un-annotated, and two clusters show resemblance to accessions that are not from animal origin. Note that one of those two latter clusters (cluster Fcc00170) occurred in all three libraries (Table 3). As with the 'bacterial clusters', those clusters are currently not discarded from the database and are submitted to GenBank. Supplementary experiments will be conducted to determine the exact origin of those clusters, and whether or not they represent contaminants.

The absence of highly expressed house-keeping genes among the five most abundant transcripts in the normalized library, suggests that the normalization procedure was successful. Without normalization more highly abundant transcripts, like tubulins, ribosomal proteins and actins, would have been sequenced (e.g. [37]). Although these sequences are present in the dataset, they do not form the list of most abundantly sequenced transcripts. For example, more than 40 ribosomal protein sequences were obtained (e.g. cluster Fcc02740), but most of these were represented by only one or two ESTs.

The prot4EST [38] script was applied to infer protein sequences (excluding the DECODER program). Putative open reading frames of the total dataset ranged between 23 and 440 amino-acids, and had an average length of 115 amino-acids. The amino acid sequences were annotated with Gene Ontology terms (GO; http://geneontol ogy.org) using the PartiGene [27] annot8r_blast2GO script (Schmid and Blaxter, personal comm.; [39]). An overview of the results of these analyses is given in Table 5 . Of the 6212 contigs 1126 contigs ( $18 \%)$ were assigned at least one GO term (expect-value $<10^{-25} ; 1025$ contigs when excluding the 140 clusters originating from yeast 
Table 3: A) Clusters that contain sequences from all three libraries and B) the most abundantly sequenced transcripts for each of the three $F$. candida cDNA libraries. $n=$ the number of sequences that are found in a cluster and that originate from the library specified. e-values for blast analyses against 'nr'-databases

\begin{tabular}{|c|c|c|c|c|c|}
\hline Library & Cluster (n) & Overview of related sequences (blastx) & Species & $\begin{array}{l}\text { GenBank } \\
\text { Accession }\end{array}$ & blastx e-value \\
\hline \multicolumn{6}{|l|}{ A. } \\
\hline \multirow[t]{10}{*}{ All three } & Fcc00I0I (5) & Hypothetical protein & Caenorhabditis elegans & CAA90252 & le-32 \\
\hline & & BCSI-like & Mus musculus & AAHI978I & $3 e-29$ \\
\hline & Fcc02080 (3) & No Significant Hit & - & & - \\
\hline & Fcc00256 (6) & No Significant Hit & - & & - \\
\hline & Fcc00343 (22) & Hypothetical protein & Aspergillus nidulans & XP_00I397474 & $1 \mathrm{e}-19$ \\
\hline & & Haloacid dehalogenase-like hydrolase & Neosartorya fischeri & XP_00I26032I & $2 e-19$ \\
\hline & & Hypothetical protein & Danio rerio & NP_001017717 & $8 e-06$ \\
\hline & Fcc0I457 (8) & Cytochrome c oxidase s.u.II & Folsomia candida & AAS 66294 & $7 e-93$ \\
\hline & Fcc03109 (3) & No Significant Hit & - & & - \\
\hline & Fcc00I70 (27) & Alpha-aminoadipyl-cysteinyl -valine synthetase & Lysobacter lactamgenus & BAA08846 & $4 e-58$ \\
\hline \multicolumn{6}{|l|}{ B. } \\
\hline \multirow[t]{5}{*}{ Normalized } & Fcc00I79 (3I) & No Significant Hit & - & & - \\
\hline & Fcc00087 (25) & No Significant Hit & - & & - \\
\hline & Fcc00I64 (16) & No Significant Hit & - & & - \\
\hline & Fcc00632 (14) & No Significant Hit & - & & - \\
\hline & Fcc00225 (I2) & GA19585-PA & Drosophila pseudoobscura & EAL32218 & $2 e-06$ \\
\hline \multirow[t]{6}{*}{ Phenanthrene } & Fcc00058 (98) & Dipeptidyl peptidase & Nasonia vitripennis & XP_00I607433 & $9 e-35$ \\
\hline & & Cytochrome P450 & Aedes albopictus & AAF97937 & $1 \mathrm{e}-12$ \\
\hline & Fcc000I5 (9I) & Cytochrome P450 & Anopheles minimus & AAN05727 & $9 e-15$ \\
\hline & Fcc0002I (35) & Monooxygenase, DBH-like I & Rattus norvegicus & AAH9I33I & $|e-2|$ \\
\hline & Fcc002I7 (25) & Monooxygenase, DBH-like I & Gallus gallus & NP_989955 & $2 e-08$ \\
\hline & Fcc04217 (23) & Cytochrome P450 & Apis melifera & XP_392000 & $3 e-12$ \\
\hline \multirow[t]{6}{*}{ Cadmium } & Fcc01017 (16) & Hypothetical protein & Ustilago maydis & XP_757859 & $5 e-13$ \\
\hline & & Endo-I,3 I,4-beta-D -glucanase precursor & Oryza sativa & $X P_{-} 480878$ & $2-07$ \\
\hline & Fcc00I70 (15) & Alpha-aminoadipyl-cysteinyl -valine synthetase & Lysobacter lactamgenus & BAA08846 & $4 e-58$ \\
\hline & Fcc0I428 (16) & I6S ribosomal RNA gene & Folsomia candida & AY55555I & le-66* \\
\hline & Fcc0II42(I2) & No Significant Hit & - & & - \\
\hline & Fcc00018 (9) & No Significant Hit & - & & - \\
\hline
\end{tabular}

*) e-value from blastn

and human mRNA from the analysis). The Partigene [27] PERL scripts were used to store all the information in a web-accessible relational database [17]. All processed ESTs, excluding the ones marked as human and yeast contamination, were submitted to dbEST (accession numbers: - ).

\section{Utility and discussion Current contents of the database}

Currently, Collembase comprises data on 8686 ESTs, which are structured in 5952 clusters. That is 6092 minus the 140 clusters from yeast and human origin. To enable easy access to the sequence dataset, the information gathered was stored in a relational database and a web-interface was created. For all clusters data is offered on (1) the ESTs within a cluster and their clone names, (2) the cDNA library from which the ESTs originated, (3) blastx and blastn hits against GenBank 'nr' databases and tblastx hits against dbEST, which all will be updated regularly, (4) the consensus sequences as generated by Phrap, and (5) the GO terms when available. Furthermore, for each cluster the BLAST results and the processed ESTs can be downloaded.

Collembase can be explored library-specific using text queries (e.g. cluster name or BLAST annotation) and by sequence similarity using a local BLAST [33] server. Furthermore, a Primer3 web-server [40] was implemented to enable PCR primer design on the assembled sequences.

\section{Future application and intended uses of the database}

Soil quality and risk assessment

The dataset presented here was generated mainly to obtain the required genomic information to construct a microarray for soil quality assessment. The array, which is based on the Agilent microarray technology, is linked to 
Table 4: Percentages of contigs showing sequence similarity (e-value $<10^{-5}$ ) with sequences stored in GenBank (nr, est databases and $\mathrm{nr}$ database restricted to the Insecta) and proteins of Caenorhabditis elegans, Drosophila melanogaster and Mus musculus (April 2007)

\begin{tabular}{llll}
\hline Database & BLAST & Significant hits for the total dataset & Significant hits excl. I40 clusters* \\
\hline $\mathrm{nr}$ & blastx & 42 & 41 \\
$\mathrm{nr}$ & blastn & 9 & 7 \\
$\mathrm{est}$ & tblastx & 40 & 39 \\
$\mathrm{nr}-$ Insecta** & blastx & 36 & 35 \\
C. elegans & blastx & 25 & 24 \\
D. melanogaster & blastx & 32 & 30 \\
M. musculus & blastx & 31 & 29 \\
\hline
\end{tabular}

* In total I40 clusters showed high similarity to yeast and human DNA sequences stored in GenBank and were therefore regarded as contamination.

** Blast analysis performed August 2007

Collembase: The 60-mer oligos printed on the chip follow the nomenclature of the clusters from which they were derived. This "linkage" enables straightforward sequence retrieval. Sequences of differentially expressed genes can be downloaded from Collembase and used in validation experiments (e.g. Q-PCR). Furthermore, in the near future we intend to store microarray and Q-PCR gene expression data as well. This freely accessible online repository will allow evaluation and analysis of the data by the scientific community (sensu [41]).

The small overlap between the toxicant enriched libraries and the normalized library (Figure 2), in combination with the higher redundancy of the toxicant enriched libraries (especially the phenanthrene library), suggests that metal and PAH exposure trigger different genes in $F$. candida. Although our expression data on $F$. candida still have to be verified by actual gene expression assays, such specificity would imply that transcription profiles contain a signature of the nature of the stress, and that different stresses can be distinguished by transcription profiling. This view is strengthened by a recent ecotoxicogenomic study by [42]. These authors showed that in the crustacean Daphnia magna different substances belonging to one chemical class (metals) can be discriminated on the basis of their characteristic expression profiles. Finally, we believe that transcription profiling will enable mechanistic insight in responses to mixtures of toxicants, a relatively new and unknown field in (eco)toxicology.

\section{Other applications}

The collembolan F. candida is frequently used in experimental studies (for a recent review see [13]), therefore Collembase could be useful outside the field of ecotoxicology as well. We expect applicability in the following research areas:

\section{Ecogenomics}

To fully disentangle the molecular mechanisms by which organisms deal with ecological challenges and environ- mental stress, additional ecologically relevant model organisms are needed [36,43]. F. candida is among a few others (e.g. free-living nematodes and earthworms $[37,44])$ one of the first soil organisms that is subject to EST sequencing. Collembase could form the basis of $F$. candida becoming a model organism in the research field of ecogenomics. F. candida has this potential as the species is easy to rear in the laboratory, reproduces parthenogenetically, has a short generation time, has a well-defined ecology and is traceable in (mesocosm) field experiments. It seems obvious that the sequence information stored in Collembase can be exploited to answer ecological questions, e.g. related to drought-tolerance, starvation and microbial resistance in soil ecosystems.

\section{Molecular ecology and population genetics}

The EST dataset presented holds information applicable in molecular ecological- and population genetic studies. For example, within the dataset 184 contigs showing one or more tandem-repeats (microsatellites) with a minimum of five repeats were discovered using the MISA PERL script [45] (Additional file 4). Within some of the clusters up to three different alleles were observed. However, due to the limited redundancy in our dataset and the fact that the libraries were constructed from animals from one parthenogenetic strain it is impossible to determine their degree of polymorphism. Still, in theory those loci are molecular markers that can be applied to unravel the forces that maintain genetic diversity and generate population genetic structure in this soil and cave inhabiting species. Furthermore, it seems obvious that the dataset and its accompanying microarray could be helpful in finding out whether transcriptional regulation is an important driver of adaptive evolution in this species.

\section{Phylogenetics and comparative genomics}

Collembola take an exceptional and fascinating position in the tree of life. Together with other basal hexapods (e.g. Protura, Diplura) they are positioned in-between the insects and crustaceans. However, recently some authors 
Table 5: GO slim terms for $F$. candida genes based on a BLAST search (e-value $\left.<10^{-25}\right)$ against the GO annotated UniProt database as generated by Annot8r_blast2GO

\begin{tabular}{llc}
\hline Description & Gene Ontology ID & Occurrences \\
\hline Biological process & & \\
\hline Electron transport & GO:0006II8 & 53 \\
Response to stimulus & GO:0050896 & 18 \\
Amino acid and derivative metabolism & GO:00065I9 & 31 \\
Behavior & GO:0007610 & 1 \\
Physiological process & GO:0007582 & 500 \\
Transport & GO:0006810 & 140 \\
Regulation of biological process & GO:0050789 & 2 \\
Cell communication & GO:0007I54 & 38 \\
Nucleobase, nucleoside, nucleotide and nucleic acid metabolism & GO:0006139 & 158 \\
Cell motility & GO:0006928 & 3 \\
Development & GO:0007275 & 30 \\
Cellular process & GO:0009987 & 6 \\
Biological process unknown & GO:0000004
\end{tabular}

Molecular function

\section{Motor activity}

Transcription regulator activity

Antioxidant activity

Signal transducer activity

Enzyme regulator activity

Catalytic activity

Binding

Nucleic acid binding

Molecular function unknown

Structural molecule activity

Transporter activity

$\begin{array}{ll}\text { GO:0003774 } & 8 \\ \text { GO:0030528 } & 8 \\ \text { GO:0016209 } & 2 \\ \text { GO:000487I } & 16 \\ \text { GO:0030234 } & 15 \\ \text { GO:0003824 } & 571 \\ \text { GO:0005488 } & 543 \\ \text { GO:0003676 } & 128 \\ \text { GO:0005554 } & 31 \\ \text { GO:0005I98 } & 82 \\ \text { GO:00052I5 } & 65\end{array}$

\section{Cellular component}

\section{Extracellular region}

Intracellular

Unlocalized protein complex

Cellular component unknown

Cell

$\begin{array}{ll}\text { GO:0005576 } & 16 \\ \text { GO:0005622 } & 444 \\ \text { GO:000594I } & 3 \\ \text { GO:0008372 } & 2 \\ \text { GO:0005623 } & 200\end{array}$

suggested that the six-legged body plan found among basal hexapods and insects evolved minimally twice (e.g. $[46,47])$. The dataset presented here might add the sequence information that is needed to gain a more detailed insight into the evolution of these groups, and the relationship between insects and crustaceans. Using the BLAST tool, Collembase can be queried for genes valuable for phylogenetic inference. Degenerate PCR primers can be developed on the retrieved sequences to obtain information on other basal hexapod groups.

\section{Conclusion}

Collembase provides EST and related data on the springtail $F$. candida. In the near future this database will be supplemented with microarray expression data. We expect that our strategy will impact soil quality testing. In addi- tion, it is clear that Collembase holds information applicable to many fields of ecological sciences (e.g. molecular ecology and ecogenomics, molecular evolution and phylogenetics).

\section{Availability and requirements}

Collembase can be accessed from URL: http://www.colle mbase.org

\section{Competing interests}

The author(s) declares that there are no competing interests.

\section{Authors' contributions}

MT participated in the experimental design, prepared the material for the normalized library, performed the bioin- 
formatics analyses and drafted the manuscript. MdB constructed the libraries enriched for stress-responsive genes. $\mathrm{TdB}, \mathrm{BN}$ and JM assisted in setting up the project, and the laboratory work. RK-L coordinated the sequencing at Greenomics, Wageningen UR. NvS participated in the conception of the study, and helped to draft the manuscript. DR participated in experimental design, supervised the project and shaped the final version of the manuscript. All authors have read and approved the final version of the manuscript.

\section{Additional material}

\section{Additional file 1 \\ The six primer pairs that were used to test the normalization procedure. Click here for file \\ [http://www.biomedcentral.com/content/supplementary/1471- 2164-8-341-S1.xls]}

\section{Additional file 2}

Sequence length distribution of different clusters in the assembled dataset. Click here for file

[http://www.biomedcentral.com/content/supplementary/14712164-8-341-S2.pdf]

\section{Additional file 3}

The clusters that were marked as putative bacterial contamination in Collembase.

Click here for file

[http://www.biomedcentral.com/content/supplementary/14712164-8-341-S3.doc]

\section{Additional file 4}

Summary of the microsatellite analysis as generated by MISA http:// pgrc.ipk-gatersleben.de/misal.

Click here for file

[http://www.biomedcentral.com/content/supplementary/1471-

2164-8-341-S4.txt]

\section{Acknowledgements}

We thank Marleen Henkens for her dedicated practical assistance at PRI Greenomics during sequencing and data management. We thank Bart van Houte, Michel Vorenhout and Sander Peters for (bio)informatics support. Furthermore, we would like to thank the three anonymous reviewers for their comments and valuable suggestions. This project was partly financed through funding from a Bsik Research grant (BSIK030II) from the Dutch Government.

\section{References}

I. Burnaford JL: Habitat modification and refuge from sublethal stress drive a marine plant-herbivore association. Ecology 2004, 85( I 0):2837-2849.

2. ROELOFS D, AARTS MGM, SCHAT H, VAN STRAALEN NM: Functional ecological genomics to demonstrate general and specific responses to abiotic stress. Functional Ecology 2007.

3. Lettieri T: Recent applications of DNA microarray technology to toxicology and ecotoxicology. ENVIRONMENTAL HEALTH PERSPECTIVES 2006, I | 4(I):4-9.
4. Bishop WE, Clarke DP, Travis CC: The genomic revolution: What does it mean for risk assessment? RISK ANALYSIS 200I, 2 I (6):983-987.

5. Neumann NF, Galvez F: DNA microarrays and toxicogenomics: applications for ecotoxicology? BIOTECHNOLOGY ADVANCES 2002, 20(5-6):391-419.

6. van Straalen NM: Ecotoxicology becomes stress ecology. ENVIRONMENTAL SCIENCE \& TECHNOLOGY 2003, 37(I 7):324A-330A.

7. Klaper R, Thomas MA: At the crossroads of genomics and ecology: The promise of a canary on a chip. BIOSCIENCE 2004, 54(5):403-4I2.

8. Snell TW, Brogdon SE, Morgan MB: Gene expression profiling in ecotoxicology. ECOTOXICOLOGY 2003, I 2(6):475-483.

9. Snape JR, Maund SJ, Pickford DB, Hutchinson TH: Ecotoxicogenomics: the challenge of integrating genomics into aquatic and terrestrial ecotoxicology. AQUATIC TOXICOLOGY 2004, 67(2): | 43- 154.

10. Volz DC, Hinton DE, Law JM, Kullman SW: Dynamic gene expression changes precede dioxin-induced liver pathogenesis in medaka fish. TOXICOLOGICAL SCIENCES 2006, 89(2):524-534.

II. Wintz H, Yoo LJ, Loguinov A, Wu YY, Steevens JA, Holland RD, Beger RD, Perkins EJ, Hughes O, Vulpe CD: Gene expression profiles in fathead minnow exposed to 2,4-DNT: Correlation with toxicity in mammals. TOXICOLOGICAL SCIENCES 2006, 94(I):7I-82.

12. Ezendam J, Staedtler F, Pennings J, Vandebriel RJ, Pieters R, Harleman $\mathrm{JH}$, Vos JG: Toxicogenomics of subchronic hexachlorobenzene exposure in Brown Norway rats. ENVIRONMENTAL HEALTH PERSPECTIVES 2004, I I 2(7):782-79I.

13. Fountain MT, Hopkin SP: Folsomia candida (Collembola): A "standard" soil arthropod. ANNUAL REVIEW OF ENTOMOLOGY 2005, 50:201-222.

14. ECOTOX_database: US EPA, Mid-Continent Ecology Division, Duluth, MN (MED-Duluth). [http://www.epa.gov/ecotox].

15. Smit CE, van Beelen P, Van Gestel CAM: Development of zinc bioavailability and toxicity for the springtail Folsomia candida in an experimentally contaminated field plot. ENVIRONMENTAL POLLUTION 1997, 98(I):73-80.

16. National Center of Biotechnology [http:// www.ncbi.nlm.nih.gov/]

17. Collembase [http://www.collembase.org]

18. Ashburner M, Ball CA, Blake JA, Botstein D, Butler H, Cherry JM, Davis AP, Dolinski K, Dwight SS, Eppig JT, Harris MA, Hill DP, IsselTarver L, Kasarskis A, Lewis S, Matese JC, Richardson JE, Ringwald M, Rubin GM, Sherlock G: Gene Ontology: tool for the unification of biology. Nature Genetics 2000, 25(I):25-29.

19. Panfilio KA, Akam M: A comparison of Hox3 and Zen protein coding sequences in taxa that span the Hox3/zen divergence. Development Genes and Evolution 2007, 2 I 7(4):323-329.

20. Zhu YY, Machleder EM, Chenchik A, Li R, Siebert PD: Reverse transcriptase template switching: A SMART (TM) approach for full-length cDNA library construction. BIOTECHNIQUES 200I, 30(4):892-897.

21. Zhulidov PA, Bogdanova EA, Shcheglov AS, Vagner LL, Khaspekov GL, Kozhemyako VB, Matz MV, Meleshkevitch E, Moroz LL, Lukyanov SA, Shagin DA: Simple cDNA normalization using kamchatka crab duplex-specific nuclease. NUCLEIC ACIDS RESEARCH 2004, 32(3):.

22. Shagin DA, Rebrikov DV, Kozhemyako VB, Altshuler IM, Shcheglov AS, Zhulidov PA, Bogdanova EA, Staroverov DB, Rasskazov VA, Lukyanov S: A novel method for SNP detection using a new duplex-specific nuclease from crab hepatopancreas. GENOME RESEARCH 2002, I 2( I 2): 1935-1942.

23. Roelofs D, Overhein L, de Boer ME, Janssens TKS, van Straalen NM: Additive genetic variation of transcriptional regulation: metallothionein expression in the soil insect Orchesella cincta. Heredity 2006, 96(I):85-92.

24. Roelofs D, Marien J, van Straalen NM: Differential gene expression profiles associated with heavy metal tolerance in the soil insect Orchesella cincta. Insect Biochemistry and Molecular Biology 2007, 37:287-295.

25. Diatchenko L, Lau YFC, Campbell AP, Chenchik A, Moqadam F, Huang B, Lukyanov S, Lukyanov K, Gurskaya N, Sverdlov ED, Siebert PD: Suppression subtractive hybridization: A method for generating differentially regulated or tissue-specific cDNA 
probes and libraries. Proceedings of the National Academy of Sciences of the United States of America 1996, 93( ( 2):6025-6030.

26. International Organization for Standardization: Soil quality-inhibition of reproduction of Collembola (Folsomia candida) by soil pollutants. ISO II 267. 1999.

27. Parkinson J, Anthony A, Wasmuth J, Schmid R, Hedley A, Blaxter M: PartiGene - constructing partial genomes. BIOINFORMATICS 2004, 20(9): I398-| 404.

28. Ewing B, Hillier L, Wendl MC, Green P: Base-calling of automated sequencer traces using phred. I. Accuracy assessment. Genome Research 1998, 8(3): $175-185$.

29. Ewing B, Green P: Base-calling of automated sequencer traces using phred. II. Error probabilities. Genome Research 1998, 8(3): $186-194$.

30. Parkinson J, Guiliano DB, Blaxter M: Making sense of EST sequences by CLOBBing them. BMC BIOINFORMATICS 2002, 3:

31. Phrap [http://www.phrap.com/]

32. Beldade P, Rudd S, Gruber JD, Long AD: A wing expressed sequence tag resource for Bicyclus anynana butterflies, an evo-devo model. Bmc Genomics 2006, 7:

33. McGinnis S, Madden TL: BLAST: at the core of a powerful and diverse set of sequence analysis tools. NUCLEIC ACIDS RESEARCH 2004, 32:W20-W25.

34. Vandekerckhove TTM, Watteyne S, Willems A, Swing JG, Mertens J, Gillis M: Phylogenetic analysis of the I6S rDNA of the cytoplasmic bacterium Wolbachia from the novel host Folsomia candida (Hexapoda, Collembola) and its implications for wolbachial taxonomy. Fems Microbiology Letters 1999, 180(2):279-286.

35. Czarnetzki $A B$, Tebbe $C C$ : Diversity of bacteria associated with Collembola - a cultivation-independent survey based on PCR-amplified I6S rRNA genes. Fems Microbiology Ecology 2004, 49(2):217-227.

36. van Straalen NM, Roelofs D: An Introduction to Ecological Genomics. Oxford, Oxford University Press; 2006.

37. Sturzenbaum SR, Parkinson J, Blaxter M, Morgan AJ, Kille P, Georgiev $O$ : The earthworm Expressed Sequence Tag project. Pedobiologia 2003, 47(5-6):447-45।.

38. Wasmuth JD, Blaxter ML: Prot4EST: Translating Expressed Sequence Tags from neglected genomes. Bmc Bioinformatics 2004, 5:.

39. BaNG Nematode and Neglected Genomics [http://www.nem atodes.org/bioinformatics/]

40. Rozen S, Skaletsky H: Primer3 on the WWW for general users and for biologist programmers. In Bioinformatics Methods and Protocols: Methods in Molecular Biology Edited by: Krawetz S, Misener S. Totowa, NJ , Humana Press; 2000:365-386.

4I. Pennie W, Pettit SD, Lord PG: Toxicogenomics in risk assessment: An overview of an HESI collaborative research program. ENVIRONMENTAL HEALTH PERSPECTIVES 2004, I I 2(4):4|7-4I9.

42. Poynton HC, Varshavsky JR, Chang B, Cavigiolio G, Chan S, Holman PS, Loguinov AV, Bauer DJ, Komachi K, Theil EC, Perkins EJ, Hughes $O$, Vulpe CD: Daphnia magna ecotoxicogenomics provides mechanistic insights into metal toxicity. Environmental Science \& Technology 2007, 4 I(3): 1044-1050.

43. Feder ME, Mitchell-Olds T: Evolutionary and ecological functional genomics. NATURE REVIEWS GENETICS 2003, 4(8):65 I-657.

44. Parkinson J, Whitton C, Schmid R, Thomson M, Blaxter M: NEMBASE: a resource for parasitic nematode ESTs. NUCLEIC ACIDS RESEARCH 2004, 32:D427-D430.

45. MISA [http://pgrc.ipk-gatersleben.de/misa/]

46. Nardi F, Spinsanti G, Boore JL, Carapelli A, Dallai R, Frati F: Hexapod origins: Monophyletic or paraphyletic? Science 2003, 299(56 | 4): | $887-1889$.

47. Carapelli A, Lio P, Nardi F, van der Wath E, Frati F: Phylogenetic analysis of mitochondrial protein coding genes confirms the reciprocal paraphyly of Hexapoda and Crustacea. BMC Evolutionary Biology 2007, 7(Suppl 2):S8.
Publish with Bio Med Central and every scientist can read your work free of charge

"BioMed Central will be the most significant development for disseminating the results of biomedical research in our lifetime. "

Sir Paul Nurse, Cancer Research UK

Your research papers will be:

- available free of charge to the entire biomedical community

- peer reviewed and published immediately upon acceptance

- cited in PubMed and archived on PubMed Central

- yours - you keep the copyright

Submit your manuscript here:

http://www.biomedcentral.com/info/publishing_adv.asp
BiolMedcentral 